\title{
ENXERTO AUTÓLOGO DE PELE, EM MALHA, COM ESPESSURA COMPLETA, NA REPARAÇÃO DE FERIDAS CARPOMETACARPIANAS DE CÃES. RESPOSTA À IRRADIAÇÃO LASER AsGa
}

\author{
AUTOLOGOUS FULL THICKNESS MESH SKIN GRAFTS, TO REPAIR WOUNDS \\ IN THE CARPAMETACARPAL REGIONS OF DOGS. INFLUENCE \\ OF LASER AsGa THERAPY
}

\section{Carlos Breno Viana Paim ${ }^{1}$ Alceu Gaspar Raiser ${ }^{2}$ Ewerton Cardoso $^{3}$ Cristiane Beck $^{3}$}

RESUMO

\begin{abstract}
O objetivo deste estudo foi avaliar clinicamente os efeitos da radiação laser AsGa, em enxertos autólogos de pele, em malha, com espessura completa, na reparação de feridas carpometacarpianas de cães. Para a seleção da amostra, escolheram-se, aleatoriamente, 20 cães que foram separados em dois grupos nos quais foi criada ferida medindo $7,5 \mathrm{~cm}^{2}$ na região carpometacarpiana. Nos animais do grupo I, a transposição realizou-se em leito receptor fresco. Os do grupo II se diferenciaram, por a enxertia ser em leito receptor contendo tecido de granulação. A região doadora foi a parede costolateral. $O$ tratamento laser AsGa foi realizado sempre no membro esquerdo, imediatamente após a transplantação perdurando por dez dias (grupo I e II). O leito receptor (grupo II) foi irradiado durante 6 dias. Os resultados indicaram diferença significativa em favor dos enxertos tratados com laser AsGa quando comparados aos enxertos testemunhas, considerando as variáveis exsudação, coloração e edema. Isso permite concluir que enxertos irradiados exibem uma pega mais avançada no estádio inicial da enxertia.
\end{abstract}

Palavras-chave: ferida, enxertos, laser AsGa.

\section{SUMMARY}

The purpose of this study was to evaluate, under gross examinations, the effects of laser AsGa, in autologous full thickness mesh skin grafts, to repair wound in the carpametacarpal regions of dogs. Twenty adult mongrel dogs were used in the present research, divided into two equal groups.

\begin{abstract}
Skin graft was apllied, in fresh wounds of the carpametacarpal regions (group I), prepared by skin excision of $7.5 \mathrm{~cm}^{2}$ in both forelimbs. The donor site was the lateral thoracic wall. At the second moment, skin graft was applied, in wounds with granulation tissue (group II). Treatment laser AsGa in the graft was done always in the left forelimbs during ten days after surgery (group I and II). The treatment with laser AsGa in the receptor site (group II) was done during six days. Grafts treated with laser AsGa, showed minor exudate and edema and rosy color when compared with untreated. The irradiated graft has improvement in the "take" in the initial phase.
\end{abstract}

Key words: wound, graft, laser AsGa.

\section{INTRODUÇÃO}

Várias técnicas cirúrgicas reconstrutivas podem ser utilizadas a fim de reparar defeitos, nos quais exista grande perda de continuidade do tegumento ou falta de elasticidade cutânea, comprometendo a cicatrização. ROGERS (1959), SWAIN (1980) e PAVLETIC (1993) citam o enxerto de pele livre, como opção corretiva nessas situações.

BRAUER \& CONVERSE (1964) consideram que a sobrevivência deste modelo de

\footnotetext{
${ }^{1}$ Médico Veterinário, Hospital Veterinário, Centro de Ciências Rurais (CCR), Universidade Federal de Santa Maria (UFSM), 97105-900, Santa Maria-RS. E-mail: brenopaim@bol.com.br Autor para correspondência.

${ }^{2}$ Médico Veterinário, Doutor, Professor Titular, Departamento de Pequenos Animais, CCR, UFSM, Santa Maria-RS.

${ }^{3}$ Médico Veterinário Santa Maria-RS.
} 
enxerto ocorre através de três processos. O processo precoce é não vascular, o qual garante nutrição através da absorção de exsudato do leito receptor. Nesse estádio, não existe circulação e o enxerto torna-se edemaciado, com aparência azulada (McGLENNON \& WHITE, 1989). Conforme BRAUER \& CONVERSE (1964), os dois outros processo são: conexão direta dos vasos do leito com os do enxerto (inosculação) e penetração de vasos do leito diretamente na derme do enxerto. BALLANTYNE et al. (1968) comprovaram que a revascularização ocorre também entre as bordas do enxerto e as do leito receptor.

Segundo SWAIN (1980), imediatamente após a enxertia, o retalho aparece pálido, devido a deficiência de elementos hemáticos. Durante os 3 dias subseqüentes, aparece azulado e só no $7^{\circ}$ dia retorna a coloração rosada, decorrente do restabelecimento circulatório normal. Para o autor, a formação das anastomoses vasculares pode acontecer já nas primeiras 24 horas após a cirurgia, porém, é mais comum que ocorra 48 horas após a enxertia.

Os enxertos de espessura completa, em malha ou tela (MILLER et $\boldsymbol{a l}$., 1991) permitem a drenagem do fluído que esteja entre o enxerto e o seu leito proporcionando maior aproximação entre os dois, e têm capacidade de expansão de 3:1 (HANSELKA, 1974). CHU et al. (1997) alcançaram uma expansão de 6:1 utilizando enxertos que continham autoepiderme e aloderme, em ratos. Segundo VANDEPUT $\boldsymbol{e t}$ al. (1997), a expansão depende de fatores pertinentes ao próprio enxerto, como também do modelo das malhas. PAVLETIC \& PEYTON (1983) relatam também que esse tipo de enxerto proporciona um aspecto cosmético de melhor qualidade, quando comparado com o de espessura parcial, porém, têm maior dificuldade de se adaptarem ao leito receptor. CLODIUS \& SMAHEL (1971) atribuem esse problema à quantidade de material biológico transplantado.

Segundo TEH (1979) e McGLENNON \& WHITE (1989), alguns pré-requisitos para o sucesso em enxertos de pele são: (1) leito receptor com vascularização adequada; (2) aproximação acurada e, (3) imobilização adequada. Para FRY et al. (1980), muitas das variáveis conhecidas e não conhecidas encontram-se envolvidas na pega de enxertos e, até hoje, pesquisas são executadas para proporcionar condições ótimas para que os enxertos sejam incorporados ao seu leito, de maneira a proporcionar mínimas alterações nas áreas enxertadas.

Nas últimas décadas, tem-se constatado o poder da radiação laser de baixa potência em acelerar o processo cicatricial. Segundo CRUAÑES (1984), esse tipo de energia, após ser depositada nos tecidos, transforma-se imediatamente em outro tipo de energia ou efeito biológico. As modificações ou efeitos que se manifestam no local de absorção e em sua volta são chamados efeitos primários. Estes provocam dois grandes resultados indiretos: estímulo microcirculatório e estímulo ao trofismo celular.

CAMBIER et $\boldsymbol{a l}$. (1996) avaliaram em ratos os efeitos da radiação laser $\mathrm{He}-\mathrm{Ne}$ e AsGa, na cicatrização de feridas de pele produzidas por queimaduras. Os resultados qualitativos entre feridas tratadas e controles foram macroscopicamente semelhantes. PIGATTO et al. (1997) estudaram a reparação cicatricial de feridas cutâneas em eqüinos, submetidos à terapia laser AsGa, comprovando o efeito modulador dessa radiação sobre o tecido de granulação evitando a proliferação exuberante, entretanto não encontraram diferença quanto ao tempo de cicatrização, nem à qualidade estética entre feridas irradiadas e não irradiadas. Já KANA $\boldsymbol{e t}$ al. (1981) registraram influência à exposição laser em feridas abertas de ratos. WANDERER (1991), estudando a radiação laser, em cicatrização cutânea, por primeira e segunda intenções, encontrou que essa radiação estimula a reparação.

Percebendo a importância da enxertia para aquelas feridas nas quais a cicatrização por primeira intenção esteja prejudicada e ainda a dificuldade para que se obtenha um percentual de pega neste procedimento, é importante que se pesquisem novos métodos de modo a melhorar os índices de pega nas enxertias. Neste artigo, é considerado o aspecto macroscópico de enxertos autólogos de pele, com espessura completa, submetidos ou não à irradiação laser AsGa, na reparação de feridas carpometacarpianas de cães.

\section{MATERIAL E MÉTODOS}

Utilizaram-se 20 cães sem raça definida, com peso médio de $10 \mathrm{~kg}$ e idade entre 1 e 3 anos, provenientes do Biotério Central da Universidade Federal de Santa Maria. Os animais foram separados, ao acaso, em dois grupos de dez. Durante todo o período experimental, foram mantidos em canis metálicos, e foi proporcionada alimentação com ração comercial e água "ad libtum". O estudo foi conduzido em uma única etapa para os cães do grupo I e em duas etapas para os do grupo II. Em ambas etapas foram tomados os mesmos cuidados pré-operatórios e de anestesia. As intervenções cirúrgicas foram nos membros torácicos.

Nos animais do grupo I, foi preparada uma ferida cirúrgica nos dois membros, medindo $7,5 \mathrm{~cm}^{2}$, abrangendo a região carpometacarpeana. Para os animais do grupo II, a ferida cutânea foi preparada de maneira similar às do grupo I. Nesse caso, porém, foi aguardada a formação do tecido de granulação por seis dias antes da enxertia, período em que a área foi 
protegida com gaze embebida em solução de nitrofurazona e enfaixada com atadura creponada, sendo esta removida diariamente para higienização da ferida com solução hidroeletrolítica balanceada.

Ato contínuo à preparação do leito receptor para a enxertia, em ambos os membros torácicos nos animais do grupo I, foi feita a colheita do retalho de pele na região torácica, destinado a ser o enxerto de pele em malha medindo $4,8 \mathrm{~cm}^{2}$. No grupo II, o leito receptor foi reavivado antes da obtenção do enxerto. Foi eleita a parede torácica lateral como a região doadora, em local onde a coloração do pelo assemelhava-se àquela das adjacências do leito receptor. Após à obtenção do retalho na área doadora, foi removido o tecido adiposo subcutâneo, com auxílio de uma tesoura de Metzembaum e, com o bisturi, foram efetuadas incisões seqüenciais, longitudinais de $0,5 \mathrm{~cm}$, a intervalos de $0,3 \mathrm{~cm}$, de modo a permitir que o enxerto exibisse o formato de uma tela ou malha.

Após irrigação do leito receptor com solução hidroeletrolítica balanceada, para retirada dos coágulos, o enxerto foi fixado através de seus vértices ao leito receptor com mononáilon $3-0$, em pontos isolados simples, tendo sido tomado cuidado para que o sentido do crescimento do pelo seguisse a mesma orientação do tecido adjacente. Em seguida, a sutura foi completada com o mesmo tipo de fio e padrão de síntese para juntar as bordas do enxerto com as do leito receptor. Para correção do defeito na área doadora, empregou-se técnica de plastia sugerida por RAISER et al. (1996).

Os enxertos foram protegidos com uma camada de gaze embebida em solução de nitrofurazona e cobertos com algodão ortopédico, após o que foi utilizada canaleta de alumínio, superposta por atadura de crepom e esparadarapo. A bandagem foi renovada diariamente, e os pontos de pele foram removidos no décimo dia de pós-operatório.

A irradiação laser iniciou-se no pós-operatório imediato, empregando-se, para tal, um laser semicondutor de baixa intensidade $^{\mathrm{a}}$. $\mathrm{O}$ aparelho empregado constitui-se de um emissor diiodo Arseneto de Gálio com comprimento de onda de $904 \mathrm{~nm}$, potência de $45 \mathrm{~mW}$ e densidade de potência média $120 \mathrm{~mW} / \mathrm{st}$.

A irradiação laser AsGa foi efetuada sempre no membro anterior esquerdo de cada animal, ficando o contralateral como testemunha. A dosimetria utilizada foi de $4 \mathrm{j} / \mathrm{cm}^{2}$ pontual e $1 \mathrm{j} / \mathrm{cm}^{2}$ em varredura. Nos animais do grupo I, o enxerto foi submetido à terapia laser durante 10 dias após ser transplantado, iniciando-se logo após a intervenção cirúrgica. Naqueles do Grupo II, o leito receptor foi submetido à terapia laser durante 6 dias, imediatamente após a realização da ferida e por mais 10 dias subseqüientes à transplantação.

Para avaliação clínica diária dos enxertos, comparando o membro irradiado com o testemunha, foi criada uma matriz de análise (Figura 1), para anotações de eventos tais como: exsudação; 2 coloração; 3 - edema; 4 - deiscências; 5 - aspecto cosmético; 6 - pega. Esses aspectos foram sempre avaliados por dois observadores.

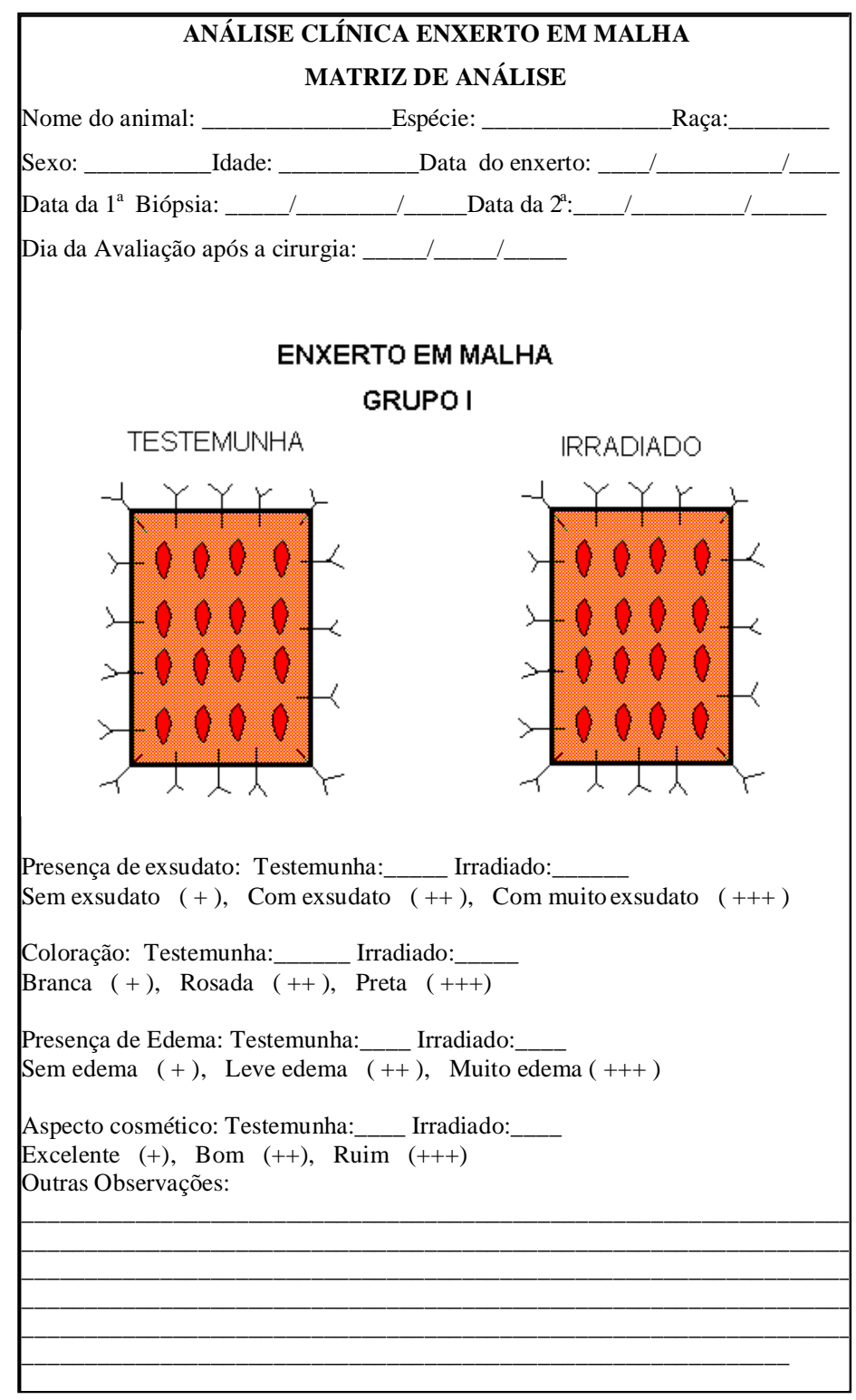

Figura 1 - Matriz de análise para obtenção dos resultados após enxertia em malha na região carpometacárpica de cães. 
Os resultados foram analisados através de delineamento experimental inteiramente casualizado, e a analise estatística pelo método do "Qui quadrado". O processamento foi feito pelo Sistema SAS (Statistic Analis Sistem) versão 6.08.

\section{RESULTADOS E DISCUSSÃO}

Quando foi realizada a enxertia nos animais do grupo II, ambos os leitos receptores irradiados e testemunhas encontravam-se totalmente cobertos por tecido de granulação. As feridas irradiadas apresentavam-se mais rosadas, com superfície em nível inferior às bordas do leito receptor e superfície plana; quando traumatizadas, sangravam com facilidade, enquanto onde controle mostravam as bordas mais edemaciadas, mais inflamadas com tecido de granulação mais espesso, chegando em certos locais, a encontrar-se mais elevados que a superfície das bordas do leito receptor (Figura 2a). Os leitos receptores irradiados mostravam maior modulação do tecido de granulação, diferindo dos achados de CAMBIER $\boldsymbol{e t}$ al. (1996). No entanto, os resultados deste estudo vão ao encontro dos achados por KANA et $\boldsymbol{a l}$. (1981), WANDERER (1991) e PIGATTO et al. (1997), segundo os quais a radiação laser AsGa afeta as fases do processo de regeneração tecidual, exercendo ação moduladora sobre o tecido de granulação.

A expansão do enxerto, obtida ao tomar a forma de malha foi de 1:1,55. Segundo DiVICENTE et al. (1969), esse fato permite compensar a desproporção entre a disponibilidade de área doadora e área receptora. Para HANSELKA (1974), isso se deve à capacidade de expansão desse modelo. Nesse trabalho, obteve-se, com o uso do bisturi, para realização das malhas uma expansão de $55 \%$, confirmando a capacidade deste enxerto de cobrir área maior que o seu tamanho original. Porém, pela falta de equipamento para um planejamento matemático para realização das malhas, as incisões com bisturi são mais afastadas umas das outras, a expansão não alcança aquela obtida por VANDEPUT et al. (1997) e CHU et al. (1997).

Quanto à presença de exsudato, observase, na tabela 1, que esse ocorreu nos enxertos do grupo I submetidos à terapia laser $\mathrm{AsGa}$, apenas no primeiro dia. A partir do segundo dia, esteve ausente em $70 \%$ deles. Por outro lado, nos enxertos controle esteve presente em $100 \%$ até o segundo dia e, em $90 \%$, até o quarto dia. Nos enxertos do grupo II, que receberam irradiação laser, sua presença deu-se em $100 \%$ dos animais, até o terceiro dia, enquanto que nos testemunhas foi de $100 \%$ até o quinto dia pós-

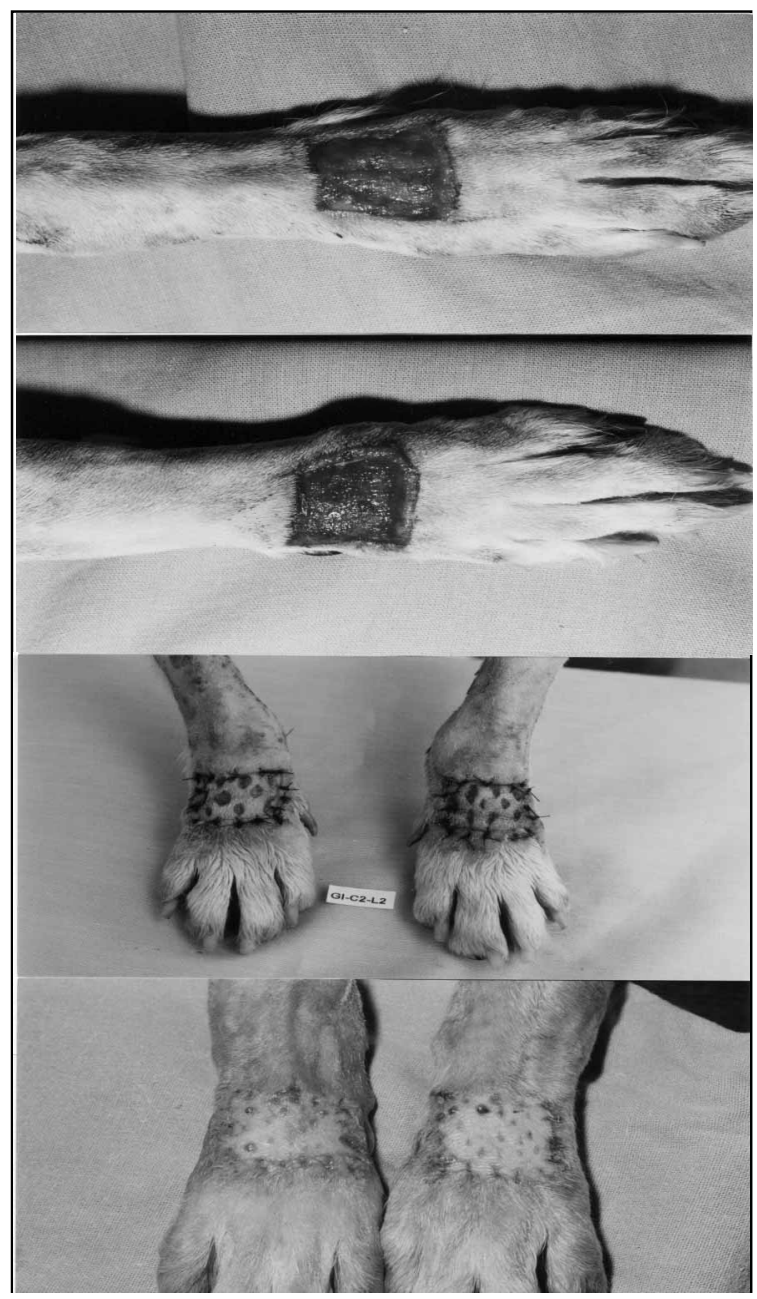

Figura 2 - A - Aspecto macroscópico do leito receptor na região carpometacarpiana dorsal (Grupo II), 6 dias após a realização da ferida: observar a coloração mais rosada e brilhosa, além da superície mais exuberante do leito receptor no membro esquerdo (irradiado) quando comparado com o direito (testemunha). B - Aspecto macroscópico da coloração de enxerto de pele, em malha, na região carpometacarpiana dorsal de cão, 2 dias após a enxertia: observar a coloração mais rosada do enxerto irradiado (membro esquerdo) quando comparado com o testemunha (membro direito). C Aspecto macroscópico de enxerto de pele, em malha, na região carpometacarpiana dorsal, submetido a irradiação laser AsGa (membro esquerdo) testemunha (membro direito), 10 dias após a enxertia: observar a epiderme epitelizada e a diminuição no tamanho das fendas.

operatório. A presença de exsudato drenando no pós-operatório ressaltou a importância das malhas em proporcionar a drenagem do líquido localizado sob o enxerto, permitindo, assim, que esse tivesse contato com o leito receptor. Segundo TEH (1979) e McGLENNON \& WHITE (1989), tais intercorrências se constituem em pré-requisitos para a pega.

Ciência Rural, v. 32, n. 3, 2002. 
Tabela 1 - Freqüência dos enxertos efetuados na região carpometacárpica de cães com sua classificação dentro da variável exsudato.

\begin{tabular}{|c|c|c|c|c|c|c|c|c|c|c|c|}
\hline \multirow{2}{*}{ Tratamento } & \multirow{2}{*}{ Grau } & \multicolumn{10}{|c|}{ Dia de avaliação } \\
\hline & & 1 & 2 & 3 & 4 & 5 & 6 & 7 & 8 & 9 & 10 \\
\hline \multicolumn{12}{|l|}{ GI* } \\
\hline & + & 10 & 70 & 80 & 70 & 80 & 80 & 80 & 80 & 80 & 80 \\
\hline \multirow[t]{3}{*}{ Laser } & ++ & 90 & 30 & 20 & 30 & 10 & 10 & 10 & 10 & 10 & 10 \\
\hline & +++ & 00 & 00 & 00 & 00 & 10 & 10 & 00 & 00 & 00 & 00 \\
\hline & + & 00 & 00 & 00 & 00 & 60 & 60 & 60 & 60 & 60 & 60 \\
\hline \multirow[t]{2}{*}{ Sem laser } & ++ & 100 & 100 & 90 & 90 & 20 & 20 & 10 & 10 & 10 & 10 \\
\hline & +++ & 00 & 00 & 10 & 10 & 20 & 10 & 10 & 00 & 00 & 00 \\
\hline \multicolumn{12}{|l|}{ GII** } \\
\hline & + & 00 & 00 & 00 & 70 & 80 & 80 & 80 & 80 & 80 & 80 \\
\hline \multirow[t]{3}{*}{ Laser } & ++ & 90 & 100 & 80 & 30 & 20 & 20 & 10 & 00 & 00 & 00 \\
\hline & +++ & 10 & 00 & 20 & 00 & 00 & 00 & 10 & 10 & 00 & 00 \\
\hline & + & 00 & 00 & 00 & 00 & 00 & 30 & 60 & 70 & 70 & 50 \\
\hline \multirow[t]{2}{*}{ Sem laser } & ++ & 100 & 100 & 100 & 100 & 100 & 70 & 30 & 10 & 10 & 10 \\
\hline & +++ & 00 & 00 & 00 & 00 & 00 & 00 & 10 & 00 & 00 & 00 \\
\hline
\end{tabular}

Pode-se observar na tabela 3 , que todos os enxertos do grupo I, tratados com laser, mostraram edema leve nos dois primeiros dias subsequientes à cirurgia, desaparecendo no terceiro dia. Por outro lado, o edema regrediu por completo nos enxertos não irradiados, apenas no quinto dia. Nos animais do grupo II, todos os enxertos irradiados apresentaram edema até o segundo dia, que se manteve em $20 \%$ dos cães no terceiro dia pós-operatório; todos os enxertos controles mostraram edema até o quinto dia, que se manteve em $80 \%$ deles no sexto dia. Essa variável, quando analisada estatisticamente, também mostrou diferença significativa $(p<0,05)$, quando se compara enxertos tratados e controles.

O estudo realizado por McGLENNON \& WHITE (1989) confirma o trabalho de BRAUER \& CONVERSE (1964), no qual o edema, até o quinto dia pós-operatório, é fruto da

A presença de exsudato, por período significativamente mais prolongado $(\mathrm{p}<0,05)$ nos enxertos não irradiados, foi atribuída à inflamação de menor intensidade obtida com o laser. Assim, pode-se inferir que a radiação laser diminui a produção de exsudato.

Nos resultados expressos na tabela 2, observa-se que $100 \%$ dos enxertos recebedores da terapia laser, tanto do grupo I como do II, apresentaram, já no primeiro dia pós-operatório, coloração rosada; entretanto, $100 \%$ dos enxertos do membro contra-lateral do grupo I mantiveram-se pálidos até o segundo dia da enxertia (Figura 2b). Nos do grupo II, a coloração rosada só se manifestou a partir do quarto dia. A análise estatística mostrou diferença significativa $(\mathrm{p}<0,05)$ entre os enxertos tratados e os testemunhas.

A presença de coloração rosada mais precoce nos enxertos irradiados, já às 24 horas após a enxertia, caracteriza a presença de elementos hemáticos nos vasos do enxerto. Atribui-se isso ao efeito bioestimulador do laser que provoca estímulo microcirculatório, além de, possivelmente, permitir que as reanastomoses vasculares ocorressem a partir de 24 horas após a cirurgia, ao contrário do que foi referido por SWAIN (1980), que relata a sua ocorrência 48 horas após a enxertia. Assim, de acordo com o estudo estatístico, pode-se inferir que a energia laser resultou em enxerto mais rosado. Para confirmar tal possibilidade, recomenda-se fazer biópsia 24 e 48 horas após implantação.

falta de circulação entre o enxerto e seu leito. Neste estudo, os enxertos não irradiados, tanto do grupo I como do II, apresentaram edema por no mínimo, cinco dias. Entretanto todos os enxertos irradiados,tanto do grupo I como do II não apresentaram mais edema a partir do terceiro dia de pós-operatório $(\mathrm{p}<0,05)$. Se forem consideradas as observações dos autores anteriores, isso caracterizou o restabelecimento mais precoce da circulação nos enxertos tratados. Esse achado permite suspeitar que houve estímulo microcirculatório, confirmando, assim, o que descreveu CRUAÑES (1984) sobre os efeitos dessa radiação.

Quanto às deiscências, estas se deram em dois dos enxertos irradiados e em três dos testemunhas no grupo I; em quatro irradiados e em três dos testemunhas do grupo II. Atribui-se isso ao excesso de tensão da pele enxertada e não à deficiência de irrigação. Estudos realizados por BALLANTYNE et al. (1968) comprovaram a existência de vasos sangüíneos ligando às bordas do enxerto às do leito, já no quinto dia após o transplante, mesmo em casos de áreas restritas de contato entre o enxerto e o seu leito; portanto, a deficiência de suprimento sangüíneo não foi a causa da deiscência. Esses achados suportam o conceito de que a tensão pode ter contribuído para ocorrência de deiscências.

O maior número de animais com deficiência estética por deficiência de epiderme ocorreu entre o quarto e o sétimo dias após a 
enxertia, como decorrência de degeneração da epiderme. Esse achado condiz com a observação de SWAIN (1980), o qual relata que a degeneração começa imediatamente após o enxerto ser removido do seu suprimento vascular, alcançando um equilíbrio entre degeneração/regeneração a partir do sétimo dia. No décimo dia após a enxertia (Figura 2c), já não mais havia diferença macroscópica entre enxerto tratado e testemunha.

\section{CONCLUSÃO}

O enxerto de pele em malha, com espessura completa é eficaz para a reparação de feridas carpometacarpianas de cães e, quando irradiado com laser de baixa potência, tem reduzida a ocorrência de exsudato e edema favorecendo a pega mais precoce em leito sem tecido de granulação. Embora a radiação laser favoreça a formação de uma superfície de granulação mais saudável, não favorece à pega do enxerto em malha de espessura completa sobre esse tecido.

\section{FONTES DE AQUISIÇÃO}

a Laser AsGa - KLD Biossistema Ltda. Comendador Guimarães, 25 - Amparo - SP.

\section{REFERENCIAS BIBLIOGRÁFICAS}

BALLANTYNE, D.L., HAWTHORNE, G.A., NATHAN, A. Effects of silastic sheet implants under simultaneous skin autografts in rats. Plastic and Reconstructive Surgery, Baltimore, v.42, n.4, p.339-342, 1968.

BRAUER, R.O., CONVERSE, J.M. Transplantation of skin. In: CONVERSE, J.M. (Editor). Reconstructive plastic surgery. Philadelphia : Saunders, 1964. V.1, Cap.2, p21-80.

CAMBIER, D.C., VANDERSTRAETEN, G.G., MUSSEN, M.J., et al. Low-power laser and healing of burns: a preliminary assay. Plastic and reconstructive surgery, Baltimore, v.97 n.3, p.555-558, 1996.

CHU, C.S., MATYLEVICH, N.P., McMANUS, A.T, et al. Optimized mesh expansion of composite skin graft in rats treated with direct current. Journal of Trauma, Baltimore, v.45, n.5, p.804-811, 1997.

CLODIUS, L., SMAHEL, J. The blood vessel system of free human skin grafts. Plastic and Reconstructive Surgery, Baltimore, v.47, n.1, p.61-66, 1971 .

** Grupo I

GI*

GII**
Tabela 2 - Frequência dos enxertos efetuados na região carpometacárpica de cães com sua classificação dentro da variável coloração.

\begin{tabular}{|c|c|c|c|c|c|c|c|c|c|c|c|}
\hline \multirow{2}{*}{ Tratamento } & \multirow{2}{*}{ Grau } & \multicolumn{10}{|c|}{ Dia de avaliação } \\
\hline & & 1 & 2 & 3 & 4 & 5 & 6 & 7 & 8 & 9 & 10 \\
\hline \multicolumn{12}{|l|}{ GI* } \\
\hline & + & 100 & 100 & 90 & 90 & 90 & 90 & 90 & 90 & 90 & 90 \\
\hline \multirow[t]{3}{*}{ Laser } & + & 00 & 00 & 10 & oo & 00 & $00^{\circ}$ & 00 & 00 & 00 & 00 \\
\hline & ++ & 00 & oo & oo & 10 & 10 & 10 & oo & oo & 00 & 00 \\
\hline & + & 00 & 00 & 80 & 70 & 70 & 70 & 70 & 70 & 70 & 70 \\
\hline \multirow[t]{2}{*}{ Sem laser } & ++ & 100 & 100 & 10 & 10 & 00 & 00 & oo & oo & 00 & 00 \\
\hline & $H$ & 00 & oo & 10 & 20 & 30 & 20 & 10 & oo & 00 & oo \\
\hline \multicolumn{12}{|l|}{ GII** } \\
\hline & + & 100 & 100 & 100 & 80 & 80 & 80 & 80 & 80 & 80 & 80 \\
\hline \multirow[t]{3}{*}{ Laser } & ++ & 00 & oo & 00 & 10 & 20 & 10 & oo & oo & 00 & oo \\
\hline & +++ & 00 & oo & oo & 10 & 00 & 10 & 20 & 10 & 00 & 00 \\
\hline & + & 10 & 10 & 10 & 00 & 90 & 80 & 80 & 80 & 80 & 80 \\
\hline \multirow[t]{2}{*}{ Sem laser } & + & 90 & 90 & 90 & 90 & 10 & 10 & 00 & 00 & oo & 00 \\
\hline & ++ & 00 & oo & oo & 10 & 00 & 10 & 20 & oo & 00 & 00 \\
\hline
\end{tabular}

+ rosado
+ + pálido
+ +

Tabela 3 - Frequiência dos enxertos efetuados na região carpometacárpica de cães com sua classificação dentro da variável edema.

\begin{tabular}{llllllllllll} 
Tratamento Grau & \multicolumn{1}{l}{\begin{tabular}{l} 
Dia de avaliação \\
\cline { 2 - 10 }
\end{tabular}}
\end{tabular}
$\begin{array}{llllllllllll}\text { Laser } & ++ & 100 & 100 & 00 & 20 & 20 & 20 & 00 & 00 & 00 & 00\end{array}$ $\begin{array}{lllllllllll}+++ & 00 & 00 & 00 & 00 & 00 & 00 & 00 & 00 & 00 & 00\end{array}$

$\begin{array}{llllllllll}00 & 00 & 10 & 10 & 80 & 80 & 70 & 70 & 70 & 70\end{array}$

$\begin{array}{llllllllllll}\text { Sem laser } & ++ & 100 & 100 & 90 & 80 & 10 & 10 & 10 & 00 & 00 & 00\end{array}$

$\begin{array}{lllllllllll}+++ & 00 & 00 & 00 & 10 & 10 & 00 & 00 & 00 & 00 & 00\end{array}$

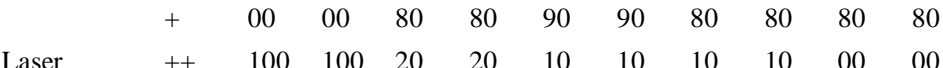
$\begin{array}{lllllllllll}+++ & 00 & 00 & 00 & 00 & 00 & 00 & 10 & 00 & 00 & 00\end{array}$

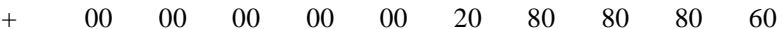

$\begin{array}{llllllllllll}\text { Sem laser } & ++ & 100 & 100 & 100 & 100 & 100 & 80 & 20 & 00 & 00 & 00\end{array}$

$\begin{array}{lllllllllll}+++ & 00 & 00 & 00 & 00 & 00 & 00 & 10 & 00 & 00 & 00\end{array}$

$\begin{array}{ll}* \text { Grupo I } & + \text { sem edema } \\ * * \text { Grupo II } & ++ \text { pouco edema } \\ \text { Significado para } \mathrm{P}<0,05 & +++ \text { muito edema }\end{array}$

CRUAÑES, J.C. La terapia láser, hoy. Barcelona : Centro Documentación láser de Meditec, 1984. 164p.

DiVINCENTI, F.C., CURRERI, P.W., PRUITT, B. A. Use of mesh skin autografts in the burned patient. Plastic and Reconstructive Surgery, Baltimore, v.44, n.5, p.464-467, 1969.

FRY, T.L., GERBE, R.W., BOTROS, S.B., et al. Effects of laser scalper, and electrosurgical excision on wound contracture and graft "take". Plastic and reconstructive surgery, Baltimore, v.65, n.6, p.729-731, 1980. 
HANSELKA, D.V. Autogenous meshgrafts in equine wound management. Journal of the American Veterinary Medical Association. Chicago. v.164, n.1, p.35-41, 1974.

KANA, J.S., HUTSCHENREITER, G., HAINA, D., et al. Effect of low-power density laser radiation on healing of open skin wounds in rats. Archives of Surgery, Chicago, v.116, n.2, p.293-296, 1981

McGLENNON, N., WHITE, R. Free skin grafting in small animals. In Practice, London, v.11, n.2, p.43-49, 1989

MILLER, C.C., FOWLER, J.D., BOWEN, C.V.A., $\boldsymbol{e}$ t $\boldsymbol{a l}$ Experimental and clinical cutaneous transfers in the dog. Microsurgery, New York, v.12, p.113-117, 1991

PAVLETIC, M.M. Atlas of small animalcreconstructive surgery. Philadelphia : Lippincott, 1993. 340p.

PAVLETIC, M.M., PEYTON, L.C. Skin. In: BOJRAB, M.J. (Editor). Current techniques in small animal surgery. Philadelphia : Lea \& Febiger, 1983. Cap.33, p.424-451.

PIGATTO, J.A.T., PIPPI, N.L., RAISER, A.G., et al. Radiações laser no tratamento por segunda intensão de feridas cutâneas em equinos. In: SEMINÁRIO LATINOAMERICANO DE CIRUGIA VETERINARIA, 3, SEMINARIO ARGENTINO DE CIRUGIA VETERINARIA, 5, e TALLER DE ENSEÑANZA DE LA CIRUGIA, 5, 1997, Corrientes, Argentina. Anais... Corrientes : UNNE, 1997. 61p. p.47.
RAISER, A.G., PAIM, C.B.V., OLIVEIRA, T.C., $\boldsymbol{e t} \boldsymbol{a l}$. Proposição de técnica para redução de feridas - Plástia segundo Raiser. In: JORNADA INTEGRADA - PESQUISA EXTENSÃO ENSINO, 3, 1996, Santa Maria, RS Resumos... Santa Maria : UFSM, 1996. 833 p. p.706.

ROGERS, B.O. Historical development of free skin grafting. The Surgical Clinics of North America, Philadelphia, v.39, n.2, p.289-311, 1959.

SWAIN, S.F. Surgery of traumatized skin: Management and reconstruction in the $d o g$ and cat. London : Saunders, 1980. 585p.

TEH, B.T. Why do skin grafts fail?. Plastic and reconstructive surgery, Baltimore, v.63, n.3, p.323-332, 1979.

VANDEPUT, J.J., TANNER, J.C., BOSWICK, J. Implementation of parameters in the expansion ratio of mesh skin grafts. Plastic and Reconstructive Surgery, Baltimore, v.100, n.3, p.653-656, 1997.

WANDERER, C. Avaliação clínica, macro e microscópica dos efeitos das radiações laser sobre o processo de cicatrização cutânea em cães. Santa Maria - RS, 1991. 69p. Dissertação (Mestrado em cirurgia) - Curso de Pós-graduação em Medicina Veterinária, Universidade Federal de Santa Maria, 1991. 